\title{
In Situ Generation of Molybdenum-Based Catalyst for Alkyne Metathesis: Further Developments and Mechanistic Insights
}

\author{
Joaquin Geng Lopez ${ }^{1}$, Maciej Zaranek ${ }^{2}$, Piotr Pawluc ${ }^{1,2}$, Régis M. Gauvin ${ }^{1}$ and André Mortreux ${ }^{1 *}$ \\ ${ }^{1}$ Univ. Lille, CNRS, Centrale Lille, ENSCL, Univ. Artois, UMR 8181 - UCCS - Unité de Catalyse et Chimie du Solide, 59000 Lille - France \\ ${ }^{2}$ Faculty of Chemistry, Adam Mickiewicz University in Poznan, Umultowska 89b, 61-614 Poznan - Poland \\ e-mail: andre.mortreux@ensc-lille.fr \\ * Corresponding author
}

\begin{abstract}
Molybdenum-based catalysts are among the best candidates to achieve alkyne metathesis. They can be either well-defined carbynes, previously synthesized before their use, but also prepared in situ upon using stable molybdenum carbonyl complexes, or high oxidation state molybdenum salts that need a previous alkylation, both type of precursors being "activated" by hydroxyl-containing compounds such as phenols and silanols. This paper is presenting studies made on these systems, directed towards the knowledge of the reaction paths leading to the active species, and in particular to define the essential role of hydroxyl-containing co-catalyst in the formation of the active species, still ill-defined. From an analysis of the byproducts formed during the reaction, as well as of the initial products, reaction paths to access catalytic carbyne species is suggested, where the ligand environment consists of phenoxy (or siloxy) groups, typically required and identified to lead to alkyne metathesis in the case of well-defined catalysts.
\end{abstract}

Résumé - Génération in situ de catalyseurs de métathèse des alcynes à base de molybdène : développements récents et approche mécanistique - Les catalyseurs à base de molybdène font partie des candidats les plus efficaces pour la métathèse des alcynes. Ceux-ci peuvent être soit des carbynes de molybdène préalablement synthétisés avant leur mise en œuvre, mais aussi préparés in situ via l'entremise de complexes à base de molybdène carbonyles, ou encore par alkylation de sels à haut degré d'oxydation, ces deux types de précurseurs nécessitant la présence de composés hydroxylés tels que des phénols ou silanols. Cette publication a pour objet de présenter des études visant à déterminer le mode de formation des espèces catalytiques impliquées dans ces deux systèmes, et en particulier du rôle du cocatalyseur hydroxylé, encore mal défini, dans la formation des espèces actives. De l'analyse des produits secondaires obtenus en cours de réaction, ainsi que des produits initiaux, on propose des voies de formation des espèces catalytiques de type carbyne, dont la particularité serait de disposer d'un environnement de ligands de type phénoxy (ou silyloxy), typiquement requis et identifiés pour favoriser le cycle catalytique relatif à la métathèse des alcynes sur des complexes carbynes bien définis. 


\section{ABBREVIATIONS}

$\begin{array}{ll}\text { acac } & \text { Acetylacetonato } \\ \mathrm{Ar} & \text { Aryl } \\ \mathrm{Bu} & \text { Butyl } \\ \mathrm{Et} & \text { Ethyl } \\ \mathrm{GC} & \text { Gas Chromatography } \\ \mathrm{OPPh}_{3} & \text { Triphenylphosphine oxide } \\ \mathrm{Ph} & \text { Phenyl } \\ \mathrm{P}(\mathrm{OPh})_{3} & \text { Triphenylphosphite } \\ \mathrm{PPh}_{3} & \text { Triphenylphosphine } \\ \mathrm{Pr} & \text { Propyl } \\ \mathrm{Py} & \text { Pyridine } \\ \mathrm{TOF} & \text { Turn Over Frequency }\end{array}$

\section{INTRODUCTION}

In 1976 was held the first metathesis symposium in Mainz, where our Nobel Laureate Yves Chauvin presented some work on tungsten-based catalysts generated from the welldefined methoxyphenyl tungsten pentacarbonyl carbene complex and $\mathrm{TiCl}_{4}$ for cyclopentene ring-opening polymerization [1]. During the same event, one of us presented some results related to the use of molybdenum hexacarbonyl as precursor for alkyne metathesis when associated with phenol as co-catalyst $[2,3]$. Since more than four decades, tremendous efforts have been devoted to the search of new catalysts for metathesis reactions in general, in particular via the synthesis and use of well-defined, active metathesis catalysts, essentially based on ruthenium, tungsten and molybdenum. In that context, a strong interest has been devoted within the last decade to the synthesis of molecular initiators for alkyne metathesis, as revealed by recent publications in the field [4-7]. However, the use of in situ catalysts still remains of interest both from academic and industrial point of views, as they are generally prepared using procedures that are less sensitive to oxygen and water, whereas the synthesis and uses of well-defined and active carbenes or carbynes would require their prior synthesis and working under more specific experimental conditions.

Since our former, seminal work on molybdenum carbonyl as catalyst precursor, our interest on the alkyne metathesis reaction has been focused in the early 80 s on the use of higher oxidation state molybdenum complexes, which when associated with an alkylating/reducing agent, and again a phenol as co-catalyst, have been shown to be two orders of magnitude more reactive than the former ones. This has been exemplified in a short series of papers where $\mathrm{MoO}_{2}(\mathrm{acac})_{2} / \mathrm{AlEt}_{3} / \mathrm{PhOH}$ combinations were shown to be active at room temperature [8] and could be applied to functionalized alkynes [9], whereas some mechanistic insights related to the catalytic reaction have been developed [10].

The aim of this paper will be to describe further in situ catalytic systems based on different high oxidation state molybdenum complexes and salts, and to show the versatility of this methodology for obtaining efficient alkyne metathesis catalysts. A careful analysis of the reaction by-products will be performed on these catalysts, as well as on $\mathrm{Mo}(\mathrm{CO})_{6} / \mathrm{ArOH}$ systems, aiming at the knowledge of the reaction paths that could lead to the active metathesis species and their ligands environment. Examination of the structure of these by-products will allow suggesting the production of aryloxy molybdenum complexes, closely similar to the wellknown carbyne complexes active in this metathesis reaction $[11,12]$.

\section{EXPERIMENTAL SECTION}

\subsection{Molybdenum Complexes Precursors}

$\mathrm{MoO}_{2}(\mathrm{acac})_{2}$ was purchased by Fluka. The complexes $\mathrm{MoCl}_{2}(\mathrm{NO})_{2} \mathrm{~L}_{2}\left(\mathrm{~L}=\mathrm{Py}, \mathrm{NEt}_{3}, \mathrm{PPh}_{3}, \mathrm{P}(\mathrm{OPh})_{3}, \mathrm{OPPh}_{3}\right)$ were prepared according to the literature, via the synthesis of polymeric $\left[\mathrm{MoCl}_{2}(\mathrm{NO})_{2}\right]_{\mathrm{n}}$, obtained by reaction between $\mathrm{Mo}(\mathrm{CO})_{6}$ and $\mathrm{NOCl}[13]$.

\subsection{Catalytic Reactions}

All reactions were carried out under argon in a reactor which typically consists of a round bottom glass flask of $c a .40 \mathrm{~mL}$ capacity equipped with a septum for sampling and sealed on a ca. $40 \mathrm{~cm}$ height, $2 \mathrm{~cm}$ diameter tube to allow condensation of the solvent during reactions conducted at high temperature ${ }^{1}$.

In a typical experiment, the molybdenum complex $(0.1 \mathrm{mmol})$ was introduced in a Schlenk tube, solubilized in $9.4 \mathrm{~mL}$ toluene and $0.6 \mathrm{~mL}$ of a molar solution of $\mathrm{AlEt}_{3}$ in toluene. The alkylation process was done at room temperature during $5 \mathrm{~min} .1 \mathrm{~mL}$ of this solution was then introduced into the reactor containing a $9 \mathrm{~mL}$ solution of $1 \mathrm{mmol}$ alkyne (4-nonyne or 4-decyne) in toluene, $1 \mathrm{mmol}$ phenol or silanol cocatalyst as well as $0.5 \mathrm{~mL}$ undecane as internal standard, previously heated at the required reaction temperature. Aliquots were taken regularly using a syringe via the septum, and immediately poured into a soda solution to stop the reaction and avoid the presence of phenol in the organic phase, which was then analyzed by GC on a Shimadzu

\footnotetext{
${ }^{1}$ This reactor model allows avoiding the presence of any trace of silicon grease, whose residual $\mathrm{Si}-\mathrm{OH}$ groups are prone to act as co-catalysts in this reaction.
} 
GC2014 apparatus equiped with a FID detector and using $\mathrm{N}_{2}$ as carrier gas. A Supelco Equity-5 column (95\% methylpolysiloxane $+5 \%$ phenylsiloxane, $30 \mathrm{~m} \times 0.32 \mathrm{~mm} \times$ $0.25 \mu \mathrm{m}$ ) was used starting at $100^{\circ} \mathrm{C}$ for $5 \mathrm{~min}$, followed by a temperature program of $20^{\circ} \mathrm{C} / \mathrm{min}$ for $5 \mathrm{~min}$, and stabilized at $200^{\circ} \mathrm{C}$. Conversions and selectivities were calculated via the internal standard method.

\subsection{By-Products Production and Analysis}

\subsection{1 $\mathrm{MoO}_{2}(\mathrm{acac})_{2} / \mathrm{AlEt}_{3} / \mathrm{PhOH}$}

In the catalytic reactor described above were introduced $2.5 \mathrm{mmol}$ phenol, $5 \mathrm{~mL}$ toluene, $1 \mathrm{mmol}$ 4-octyne and $0.1 \mathrm{~mL}$ undecane. After complete solubilization of phenol, the catalyst was prepared as before, and all the alkylated molybdenum solution (corresponding to $0.1 \mathrm{mmol} \mathrm{Mo}$ ) was introduced at room temperature; aliquots were taken from time to time to follow the evolution of the by-products formation and analyzed by GC-MS.

\subsection{2 $\mathrm{Mo}(\mathrm{CO})_{6} / \mathrm{ArOH}$}

$0.05 \mathrm{mmol}$ of $\mathrm{Mo}(\mathrm{CO})_{6}, 1 \mathrm{~mL}$ of toluene, $0.5 \mathrm{mmol}$ of 4-octyne, $0.5 \mathrm{mmol}$ of phenol or chlorophenol and $100 \mu \mathrm{L}$ of undecane were introduced in the reactor. The mixture was stirred and heated at $110^{\circ} \mathrm{C}$. Samples were taken and analyzed using the GC-MS apparatus described below.

\subsubsection{GC/MS Analysis}

GC-MS analyses were performed on a Bruker SCION436GC - Bruker SCION SQ MS equipped with a $0.25 \mathrm{~mm}, 30 \mathrm{~m}$-long Agilent DB-5 capillary column. The carrier gas was helium using a column flow of $1.0 \mathrm{~mL} / \mathrm{min}$ and a temperature program of $10^{\circ} \mathrm{C} / \mathrm{min}$ starting at $60^{\circ} \mathrm{C}$ (hold $3 \mathrm{~min}$ ) and ending at $250^{\circ} \mathrm{C}$ (hold $13 \mathrm{~min}$ ); EI: $70 \mathrm{eV}$.

\section{RESULTS AND DISCUSSION}

Within the frame of this paper, we will first present and compare catalytic results that have been observed on catalytic systems based on high oxidation state dioxo and dinitrosyl molybdenum/ $/ \mathrm{AlEt}_{3} / \mathrm{ZOH}$ catalysts for alkyne metathesis, with regard to the use of various and selected ligand environment. A second part will be devoted to analysis of the byproducts of these reactions, as well as those observed on molybdenum hexacarbonyl/ArOH catalysts. Mechanistic considerations will be made, leading to the assumption that the co-catalyst should give rise to the formation of high oxidation state catalysts in both cases.

\subsection{Dinitrosyl Molybdenum Based Catalysts}

As described in a previous paper [8], the $\mathrm{MoCl}_{2}(\mathrm{NO})_{2}(\mathrm{Py})_{2} /$ $\mathrm{AlEt}_{3} / \mathrm{PhOH}$ combination is an active and selective catalyst for 4-nonyne metathesis at toluene reflux, the reaction being at equilibrium within minutes at a $\mathrm{C} \equiv \mathrm{C} / \mathrm{Mo}$ ratio of 100 (Eq. 1):

$$
\begin{aligned}
2 \mathrm{C}_{3} \mathrm{H}_{7} \rightleftharpoons \mathrm{C}_{4} \mathrm{H}_{9} \rightleftharpoons & \mathrm{C}_{3} \mathrm{H}_{7}=\mathrm{C}_{3} \mathrm{H}_{7} \\
& +\mathrm{C}_{4} \mathrm{H}_{9} \equiv \mathrm{C}_{4} \mathrm{H}_{9}
\end{aligned}
$$

The association of dinitrosyl molybdenum complexes/ chloroalkylaluminum reagents to produce alkene metathesis catalysts has been known for a long time, as the first paper in the field has appeared very early in the corresponding literature, when the reaction was so called "disproportionation" $[14,15]$. Of interest in the corresponding papers is that a comparison was made using molybdenum versus tungsten dinitrosyl complexes. This led to the conclusion that molybdenumbased catalysts are more reactive, and that the use of different ancillary, two-electron donor ligands also led to various activities. In line with these results, we performed metathesis reactions on 4-nonyne using the same procedure as described above, with different phosphorus and nitrogen ligands, using phenol as standard co-catalyst. The reactions were all run at $110^{\circ} \mathrm{C}$ for comparison. All reactions led to the equilibrium within minutes, with a complete selectivity into 4-octyne and 5-decyne. The results are reported in Table 1.

The use of chlorobenzene as solvent only affects the reactivity to a small extent, and a comparison of the results obtained on the different pre-catalysts leads to the conclusion that the less coordinating ligands triethylamine and triphenylphosphine oxide gave the best results. It must be emphasized that using polymeric $\left[\mathrm{Mo}_{2} \mathrm{Cl}_{2}(\mathrm{NO})_{2}\right]_{n}$ gave also good results (entry 6), but due to the poor solubility of this precursor in toluene, the activation procedure needed a much longer reaction time with the alkylating reagent $\mathrm{AlEt}_{3}$, as exemplified by the evolution of the activity versus alkylation time at $60^{\circ} \mathrm{C}$ (Tab. 2).

TABLE 1

Activity of the $\mathrm{MoCl}_{2}(\mathrm{NO})_{2} \mathrm{~L}_{2} / \mathrm{AlEt}_{3} / \mathrm{PhOH}$ for 4 -nonyne metathesis

\begin{tabular}{c|c|c|c|c|c|c}
\hline Entry & 1 & 2 & 3 & 4 & 5 & 6 \\
\hline $\mathrm{L}$ & Pyridine & $\mathrm{NEt}_{3}$ & $\mathrm{PPh}_{3}$ & $\mathrm{P}(\mathrm{OPh})_{3}$ & $\mathrm{OPPh}_{3}$ & None \\
\hline TOF $\left(\mathrm{h}^{-1}\right)^{\mathrm{a}}$ & 3300 & 4400 & 3950 & $3700^{\mathrm{c}}$ & 4750 & $3600^{\mathrm{d}}$ \\
\hline TOF $\left(\mathrm{h}^{-1}\right)^{\mathrm{b}}$ & 2150 & 3000 & 3650 & $2400^{\mathrm{c}}$ & 3800 & $3600^{\mathrm{d}}$ \\
\hline
\end{tabular}

Conditions: $T=110^{\circ} \mathrm{C} ;[\mathrm{C} \equiv \mathrm{C}] /[\mathrm{Mo}]=100 ;\left[\mathrm{AlEt}_{3}\right] /[\mathrm{Mo}]=6 ;$ $\mathrm{PhOH} / \mathrm{Mo}=100$.

a Toluene as solvent.

${ }^{\mathrm{b}}$ Chlorobenzene as solvent.

c Selectivity into metathesis products decreases to $50 \%$.

${ }^{\mathrm{d}}$ The use of a longer activation time was necessary (Tab. 2 below). 
TABLE 2

Evolution of the 4-nonyne metathesis rate versus the activation time of $\left[\mathrm{Mo}_{2} \mathrm{Cl}_{2}(\mathrm{NO})_{2}\right]_{n}$

\begin{tabular}{c|c|c|c|c|c|c|c}
\hline $\begin{array}{c}\text { Activation time } \\
(\mathrm{min})\end{array}$ & 5 & 10 & 20 & 30 & 40 & 50 & 60 \\
\hline TOF $\left(\mathrm{h}^{-1}\right)$ & 57 & 78 & 200 & 360 & 385 & 465 & 516 \\
\hline
\end{tabular}

Conditions: Same as in Table 1, toluene as solvent. $T=60^{\circ} \mathrm{C}$.

An interesting feature to be noticed is the fact that with all catalytic systems, a further loading of alkyne was immediately metathesized to equilibrium, thus demonstrating the robustness of such systems.

\subsection{Catalytic Results on the $\mathrm{MoO}_{2}(\mathrm{acac})_{2} / \mathrm{AlEt}_{3} / \mathrm{ArOH}$ or $\equiv \mathrm{Si}-\mathrm{OH}$ Catalysts}

The $\mathrm{MoO}_{2}(\mathrm{acac})_{2} / \mathrm{AlEt}_{3} / \mathrm{PhOH}$ combination developed earlier $[8,10]$ has been the subject of some studies in this reaction. This section will first give data related to the effect of alkyne/Mo ratio, and in a second part will study the effect of the nature of the hydroxyl-containing co-catalyst on the reaction rate.

\subsubsection{Effect of the Alkyne Concentration on the Reaction Rate}

The evolution of the reaction rate versus the co-catalyst concentration has already been described, showing that the reaction was following a kinetic law in which a first order had to be applied to the phenol co-catalyst [8]. Of interest would also be to know the effect of the alkyne/Mo ratio on the activity, using constant concentration of molybdenum $\left(10^{-3} \mathrm{M}\right)$ and phenol $\left(10^{-1} \mathrm{M}\right)$. These reactions were conducted at $110^{\circ} \mathrm{C}$ (Tab. 3).

The evolution of the turnover frequency confirms that the reaction rate law is first order in alkyne, what was expected if considering the previous results already found at $60^{\circ} \mathrm{C}[10]$. It has to be emphasized that this result corresponds to a 15 -fold increase of the turnover rate upon increasing the temperature from 60 to $110^{\circ} \mathrm{C}$. Such high values $\left(40 \mathrm{~s}^{-1}\right)$ are more relevant to a "very high" activity rating on single site ethylene polymerization catalysts [16], and to the best of our knowledge, have no precedent in the field of alkyne metathesis.

Applying this catalytic system to functionalized alkynes have proved to be successful in some cases: using a substrate/ $\mathrm{PhOH} / \mathrm{Mo}$ ratio of $1000 / 100 / 1$, the non-conjugated enyne 1-nonene-4-yne was successfully metathesized on the triple bond, the terminal double bond remaining intact, with a turnover rate of $1680 \mathrm{~h}^{-1}$. The chloro-substituted 7-chloro3-heptyne had a reactivity similar to that of the alkyl disubstituted alkynes, affording turnover rates of $60000 \mathrm{~h}^{-1}$ [9].
TABLE 3

Effect of alkyne/Mo ratio on reaction rate on the $\mathrm{MoO}_{2}(\mathrm{acac})_{2} / \mathrm{AlEt}_{3} / \mathrm{PhOH}$ catalyst at $110^{\circ} \mathrm{C}$

\begin{tabular}{c|c|c|c|c|c|c|c}
\hline $\begin{array}{c}\text { 4-nonyne/ } \\
\text { Mo }\end{array}$ & 10 & 100 & 200 & 500 & 1000 & 1500 & 2000 \\
\hline $\begin{array}{c}\text { TOF } \\
\left(\mathrm{h}^{-1}\right)\end{array}$ & 650 & 7000 & 12700 & 32000 & 62500 & 100250 & 144000 \\
\hline
\end{tabular}

Conditions: solvent: toluene; $[\mathrm{Mo}]=10^{-3} \mathrm{M} ;\left[\mathrm{AlEt}_{3}\right] /[\mathrm{Mo}]=6 ;[\mathrm{PhOH}]=$ $10^{-1} \mathrm{M} ; T=110^{\circ} \mathrm{C}$.

As compared with the $\mathrm{MoCl}_{2}(\mathrm{NO})_{2} \mathrm{~L}_{2}$ catalyst reported above, a comparison can be made using the results observed at $110^{\circ} \mathrm{C}$ with a $100 / 100 / 1(\mathrm{C} \equiv \mathrm{C} / \mathrm{PhOH} / \mathrm{Mo})$ ratio (Tab. 3), the bis (acetylacetonato) dioxomolybdenum compound being ca 1.5 times more active than the best bis-(triphenylphosphine oxide) dichlorodinitrosylmolybdenum complex (Tab. 1, entry 5).

\subsubsection{Effect of Different Co-Catalysts on the Reaction Rate}

Since its discovery, the original $\mathrm{Mo}(\mathrm{CO})_{6} /$ resorcinol catalyst have been the subject of variations on the nature of the co-catalyst. Phenol itself and chlorophenol, as well as silanols and fluoro alcohols were rapidly recognized as suitable to activate the reaction, and revealed that such hydroxylcontaining compounds were essential for the reaction to proceed [17]. Following this paper, several reports aimed at the search for the best co-catalyst to be used for these in situ systems have appeared in the literature, for classical metathesis reactions conducted on disubstituted alkynes [18], and also for comparisons between the $\mathrm{MoO}_{2}(\mathrm{acac})_{2} / \mathrm{AlEt}_{3} / \mathrm{ArOH}$ and the $\mathrm{Mo}(\mathrm{CO})_{6} /$ phenol catalytic systems applied to polymerization reaction of aromatic diynes [19]. In this paper were also reported data where different fluoro-substituted phenols were used, confirming that the use of different co-catalysts results in different reaction rates.

Our objective has then been to look for the effect of variation of the phenol/silanol $(\mathrm{ZOH})$ co-catalyst on the reaction rate during metathesis of 4-decyne on alkylated $\mathrm{MoO}_{2}(\mathrm{acac})_{2} / \mathrm{AlEt}_{3} / \mathrm{ZOH}$ system. For this study, we deliberately chose to conduct the reactions at $20^{\circ} \mathrm{C}$, so as to obtain more accurate results in terms of comparison. These results using 4-decyne as substrate are reported in Table 4, and Figure 1 presents the kinetic profiles of the reactions.

Upon analysis of these results, it appears that although the best initial activity is achieved with $o$-fluorophenol, 3 - and 4-chlorophenol gave rise to higher global turnovers, although none of the reactions is going to equilibrium. In some cases (entries 3 and 10), such a comparison is useless at this temperature, as the co-catalysts are only sparingly soluble or insoluble in toluene: any conclusion about their potential behavior as activator at higher temperature must therefore be excluded. It must be noticed however that the 
TABLE 4

Initial activity and conversion of the $\mathrm{MoO}_{2}(\mathrm{acac})_{2} / \mathrm{AlEt}_{3} / \mathrm{ZOH}$ for 4-decyne metathesis

\begin{tabular}{c|c|c|c|c}
\hline Entry & Co-catalyst & pKa & TOF $\left(\mathrm{h}^{-1}\right)$ & Conversion (\%) \\
\hline 1 & $2,3,4,5,6-\mathrm{F}_{5}-\mathrm{ArOH}$ & 5.35 & 0 & - \\
\hline 2 & $3,4-\mathrm{Cl}_{2}-\mathrm{ArOH}$ & 8.5 & 53 & 26 \\
\hline 3 & Resorcinol ${ }^{\mathrm{a}}$ & 9.1 & 0 & - \\
\hline 4 & $2-\mathrm{F}-\mathrm{ArOH}$ & 8.7 & 76 & 26 \\
\hline 5 & $3-\mathrm{Cl}-\mathrm{ArOH}$ & 8.9 & 59 & 33 \\
\hline 6 & $4-\mathrm{Cl}-\mathrm{ArOH}$ & 9.3 & 56 & 30.5 \\
\hline 7 & $\mathrm{ArOH}$ & 9.9 & 22 & 19 \\
\hline 8 & $2,6-\left(\mathrm{CH}_{3}\right)_{2}-\mathrm{ArOH}$ & 10.6 & 0 & - \\
\hline 9 & $\left(\mathrm{C}_{6} \mathrm{H}_{5}\right)_{3} \mathrm{SiOH}$ & $\sim 12^{\mathrm{b}}$ & 12.5 & 5.0 \\
\hline 10 & $\left(\mathrm{C}_{6} \mathrm{H}_{5}\right)_{2} \mathrm{Si}(\mathrm{OH})_{2}{ }^{\mathrm{a}}$ & $\sim 12^{\mathrm{b}}$ & 0 & - \\
\hline 11 & $\left(\mathrm{CF}_{3}\right)\left(\mathrm{CH}_{3}\right)_{2} \mathrm{COH}$ & 11.8 & 0 & - \\
\hline 12 & $\left(\mathrm{CF}_{3}\right) \mathrm{CH}{ }_{2} \mathrm{OH}$ & 12.5 & 0 & - \\
\hline $\mathrm{C}$ & & & 0 & \\
\hline
\end{tabular}

Conditions: $T=20^{\circ} \mathrm{C}$, solvent: toluene; $[\mathrm{C} \equiv \mathrm{C}] /[$ phenol or silanol $]=1$; $[\mathrm{C} \equiv \mathrm{C}] /[\mathrm{Mo}]=100 ;\left[\mathrm{AlEt}_{3}\right] /[\mathrm{Mo}]=6$.

${ }^{\mathrm{a}}$ Insoluble in toluene.

${ }^{\mathrm{b}}$ Estimated value of the pKa.

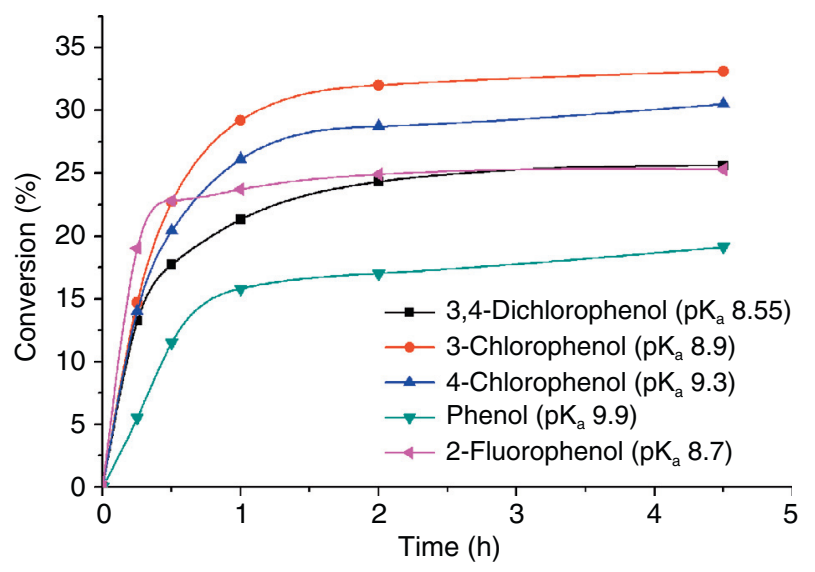

Figure 1

Reaction profiles during 4-decyne metathesis using different co-catalysts in the $\mathrm{MoO}_{2}(\mathrm{acac})_{2} / \mathrm{AlEt}_{3} / \mathrm{Z}-\mathrm{OH}$ systems. See Table 4 for conditions.

more acidic halogeno-substituted phenols are much better than phenol, as found earlier on $\mathrm{Mo}(\mathrm{CO})_{6} / \mathrm{ArOH}$-based catalysts $[17,18]$, although no direct relationship between the activity and the $\mathrm{pKa}$ value of the co-catalysts could be found. This is similar to what was observed in several cases where a systematic study of the reactivity of in situ generated catalysts was conducted. These include the thermally activated $\mathrm{Mo}(\mathrm{CO})_{6} / \mathrm{ArOH}$ catalysts during ring-closing metathesis of a functionalized diyne [18], as well the screening of alcohols and phenols for the in situ synthesis of aryloxymolybdenum carbyne complex from trisamido molybdenum alkylidynes, where again the authors have found that no correlation could be found between the phenol/alcohol $\mathrm{pKa}$ values and the performance in ring-opening polymerization of ring-strained dibenzo[a,e]-8-annulene [20].

It appears from these results that the high oxidation state molybdenum/ $\mathrm{AlEt}_{3} / \mathrm{ArOH}$-based catalytic systems are by far much more reactive than thermally activated $\mathrm{Mo}(\mathrm{CO})_{6} / \mathrm{PhOH}$, for which, using phenol as activator, a turnover frequency of $120 \mathrm{~h}^{-1}$ was found (versus $7000 \mathrm{~h}^{-1}$ ) [8].

\subsection{Mechanistic Insights}

\subsubsection{Previous Mechanistic Considerations}

The reaction mechanism of these in situ catalytic systems based on molybdenum/ArOH combinations has been the subject of part of a review [21] where considerations using previous results on the $\mathrm{MoO}_{2}(\mathrm{acac})_{2} \mathrm{AlEt}_{3} / \mathrm{PhOH}$ combination in our group led to the conclusion that transient metallacyclobutenes might be key intermediates of the catalytic cycle [11, 12].

This hypothesis was supported by several observations which are:

- the detection of alkenes at the beginning of the reaction, arising from a reaction between an ethylidene metallacarbene initially formed during the alkylation step of the molybdenum salt by triethylaluminum;

- the fact that a first order reaction rate in phenol was established [8];

- the occurrence of an interaction via H-bonding between the proton of the hydroxyl group of the phenolic cocatalyst and the alkyne triple bond [17, 22, 23].

On the other hand, a mechanism involving the occurrence of metallacarbynes as active species and metallacylobutadiene intermediates in this metathesis has been first suggested by Katz and McGinnis [24], and established by McCullough and Schrock via the synthesis of well-defined tris-aryloxy molybdenum complexes [25].

Considering the fact that the reaction of $\mathrm{Mo}(\mathrm{acac})_{3}$ with triethylaluminum reduces the molybdenum salt to $\operatorname{Mo}(0)$, as attested by the synthesis and successful use of Chatt's complex $\mathrm{Mo}\left(\mathrm{N}_{2}\right)_{2}$ (dppe), successfully used as precatalyst in the presence of phenol [9], we anticipated that in some way, the hydroxyl containing co-catalyst should react on molybdenum to provide higher oxidation state molybdenum species, more prone to provide active metathesis catalysts.

The question was then to know how such Mo species can be produced: the following section, dealing with a deeper 
examination of the by-products formed during the reaction will try to give some answers to this key problem.

\subsubsection{Analysis of the By-Products Formed during Metathesis}

As stated before, we had analyzed the initial by-products at the early stage of the alkyne metathesis using $\mathrm{MoO}_{2}(\mathrm{acac})_{2} / \mathrm{AlEt}_{3} / \mathrm{ArOH}$ as catalyst $[11,12]$. However, analyzing more carefully the GC chromatograms conducted at higher temperature revealed that small amounts of higher molecular weight products - in sub-stoichiometric quantities versus the catalyst - were also formed.

We were therefore interested to analyze these reaction byproducts, as determination of their nature could provide some elements related to the formation of the active species.

To avoid the presence of too many products arising from the occurrence of the metathesis process, the reactions were conducted using a symmetrical alkyne, 4-octyne, and GC/MS analysis was then applied to assign their structure. Compounds 1, 2, 3 and 4 were formed (Fig. 2).

Analyzing their relative amounts indicates that substituted butadienic compounds $\mathbf{1}$ and $\mathbf{3}$ are produced in higher amounts than the cyclotrimer $\mathbf{2}$, whereas this aromatic trimer becomes the major compound in the absence of phenol.

This observation prompted us to use a similar procedure aimed at the search for similar products when using our former $\mathrm{Mo}(\mathrm{CO})_{6} / \mathrm{ArOH}$ catalyst. Compounds $\mathbf{1 ,} \mathbf{2}$ and $\mathbf{3}$ were also indeed produced, together with compounds $\mathbf{5}$ and $\mathbf{6}$.

In Figure 3 are reproduced in the upper part of the GC spectrum of a reaction conducted for $4 \mathrm{~h}$ at toluene reflux, using 10 eq 4-octyne versus $\mathrm{Mo}(\mathrm{CO})_{6}$, with and without chlorophenol.

Remarkably, the comparison of the GC chromatograms reveals several interesting features:

- one may find once more in the GC analysis $\mathbf{1}$ and $\mathbf{2}$ as the major products;

- the relative amount of aromatic trimer versus the butadienic compounds slightly decreases when using the phenolic reagent;

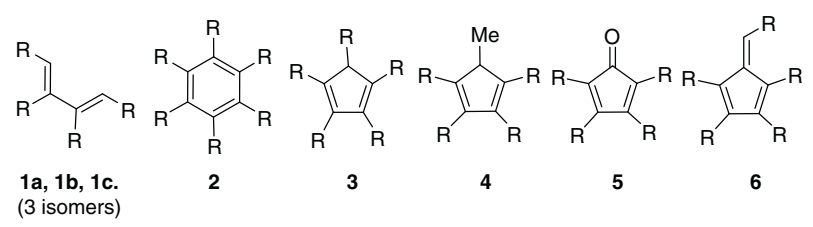

Figure 2

Reaction by-products observed during metathesis of 4-octyne on $\mathrm{MoO}_{2}(\mathrm{acac})_{2} / \mathrm{AlEt}_{3} / \mathrm{PhOH}$ and $\mathrm{Mo}(\mathrm{CO})_{6} / \mathrm{ArOH}$ catalytic combinations $(\mathrm{R}=\mathrm{Pr})$.
- worth to mention is also the fact that using $\mathrm{Mo}(\mathrm{CO})_{6}$ without activator, after longer time $(8 \mathrm{~h})$, the tetrapropylcyclopentadienone $\mathbf{5}$ and the butylidene tetrapropylcyclopentadiene $\mathbf{6}$ were produced in larger amounts than when using the phenolic compound.

\subsubsection{Discussion}

The co-production of tetra-substituted butadienic compounds $\mathbf{1}$ and aromatic cyclotrimers $\mathbf{3}$ from disubstituted alkynes is scarcely described in the literature. One of these involves the use of $\mathrm{MoCl}(\mathrm{CO})_{2}\left(\eta^{3}-\mathrm{C}_{3} \mathrm{H}_{5}\right)(\mathrm{NCMe})_{2}$, which converts 6 eq of $\mathrm{PhC} \equiv \mathrm{CPh}$ when heated in methanol at reflux for $24 \mathrm{~h}$ into a mixture of hexaphenylbenzene (58\%) and $(E, E)-1,2,3,4$-tetraphenylbutadiene (34\%) [26]. More relevant to our concern is an attempt to establish the catalytic mechanism of the alkyne metathesis on $\mathrm{Mo}(\mathrm{CO})_{6} / \mathrm{ArOH}$ catalyst by Nishida et al. [27], who also reported the synthesis of butadienic compounds as minor products during the cross metathesis reaction between symmetrical alkyne and a dialkyne, affording mainly the aromatic $[2+2+2]$ co-cyclization product. This reaction was done using a huge amount of "catalyst" ( $35 \mathrm{~mol} \%$ ), and the author suggested that the production of both compounds should arise from transient metallacyclopentadienes intermediates, which were also suggested to be key intermediates for metathesis, via a hypothetic scrambling of the alkyl groups on the metallacycle via cyclobutadienic complexes and reverse reaction [28] (Fig. 4).

The expansion of the metallacycle via insertion of a third alkyne would produce the aromatic compound after reductive elimination. In this paper however, there has been no discussion about the role of the co-catalyst in the catalytic process, neither on the molybdenum ligand environment.

From that point of view, some proposals were made by several authors, where the phenolic co-catalyst would react on molybdenum species, leading to aryloxy-molybdenum carbynes of $(\mathrm{ArO})_{3} \mathrm{Mo} \equiv \mathrm{CR}$ type $[26,29,30]$. However, in no case was reported the identification of such species, and how they could be formed from the reaction mixture consisting of $\mathrm{Mo}(\mathrm{CO})_{6}$ and phenols.

The observation of the formation of butadienic compounds $\mathbf{1}$ in the medium is a key feature on which we then focused our attention, and isotopic labeling experiments have been performed using deuterated phenol to probe whether a protonolysis (deuterolysis) of the metallacyclopentadienic intermediates could occur. This procedure has already been used by Ibragimov et al. to provide evidence for the formation of aluminometallacycles in reactions involving alkynes and diethylaluminum chloride [31].

Indeed, this reaction leads to the production of partly deuterated 1,2,3,4-tetrapropylbutadiene (Fig. 5)

Our assumption and hypothesis is therefore that compounds $\mathbf{1}$ arise from a reaction between the tetra-alkyl 


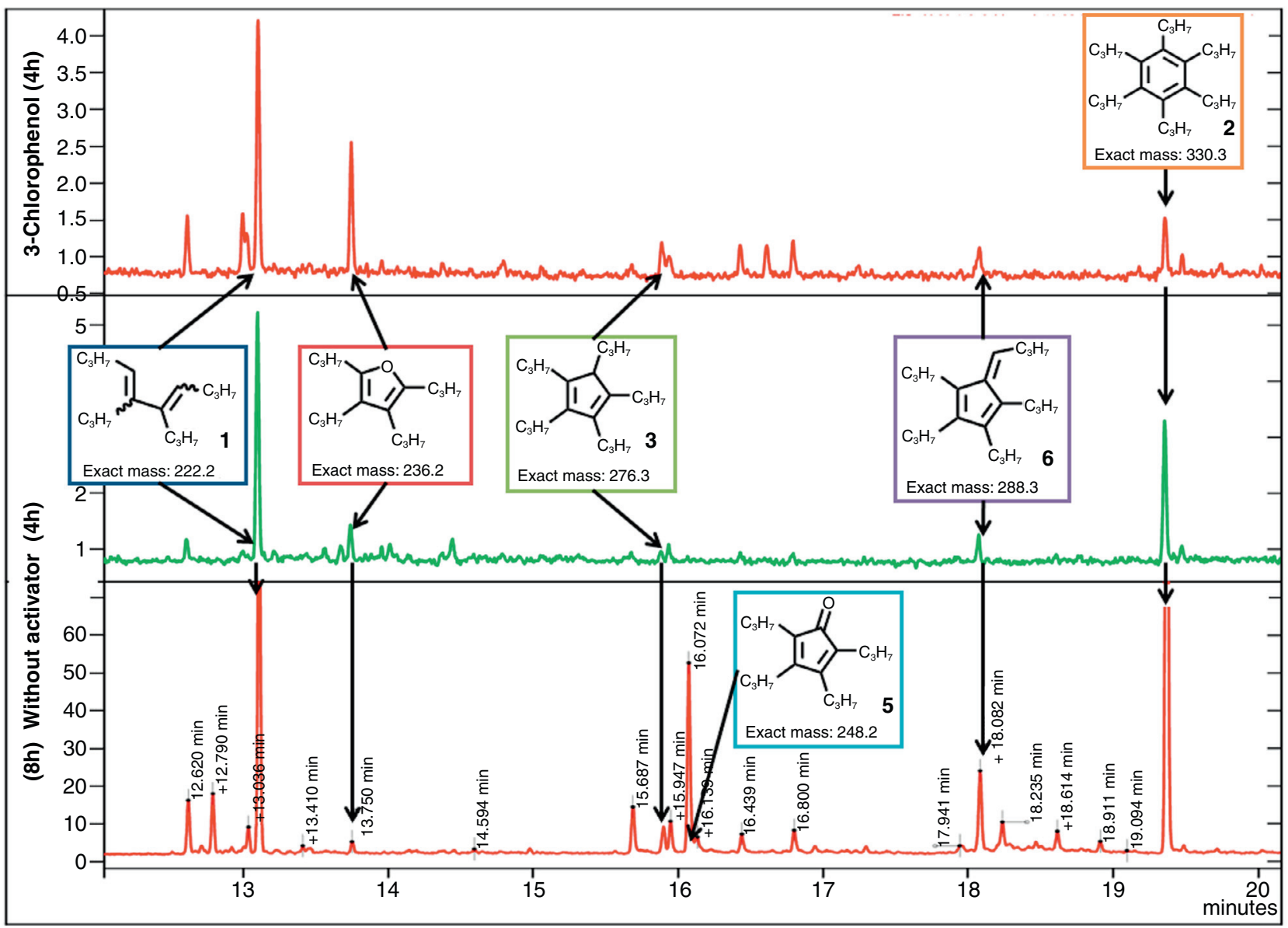

Figure 3

GC chromatogram of the higher molecular weight products obtained upon heating $\mathrm{Mo}(\mathrm{CO})_{6}$ and 4-octyne with and without phenol at toluene reflux for 4 and $8 \mathrm{~h}$.

cyclopentadienyl molybdenum intermediates and excess phenol, which in turn should also produce aryloxy-molybdenum species. Worth to be reminded at this point is the fact that the kinetic studies have shown a first order dependence of the reaction rate in phenol concentration, which may here be justified, if considering that this protonolysis reaction would be the rate determining step. Among others such as triphenylsiloxy molybdenum carbynes recently studied in depth by Heppekausen et al. [32], these aryloxy species are known to be ideal ligands to provide active molybdenum carbyne complexes for alkyne metathesis, as compared with tungsten-based catalysts [33]. Figure 6 is representative of the preceding hypothesis, where the production of a $(\mathrm{PhO})_{2} \mathrm{Mo}$ transient intermediate is therefore suggested, following the preliminary molybdenacyclopentadiene complex formation.

This hypothesis does not preclude the possibility of formation the aromatic trimers, which can be produced by a further insertion of alkyne into the cyclometallated species as a competitive reaction. Of interest is also the fact that use of phenol avoids the production of the cyclopentadienone by-product: an insertion reaction of remaining $\mathrm{CO}$ moieties in the metallacyclopentadienyl molybdenum species would indeed lead to this ketone after reductive elimination, a process that is in competition with the protonolysis reaction. The production of tetraphenyl-substituted cyclopentadienone molybdenum complexes was reported very early by Hübel and Merenyi [34] during a reaction involving diphenylacetylene and $\mathrm{Mo}(\mathrm{CO})_{6}$ at high temperature, where other dinuclear molybdenum cyclobutadienic complexes were synthesized [34] and well-characterized by Potenza et al. [35]. Notably also in the synthesis of these complexes is the fact that pentaphenylcyclopentadiene and $\left(\mathrm{Ph}_{5} \mathrm{C}_{5}\right)_{2} \mathrm{Mo}$ were also produced, which corresponds in our case to compound 3. Furthermore, with regard to this hypothesis, one may also consider our previous observations made on the 


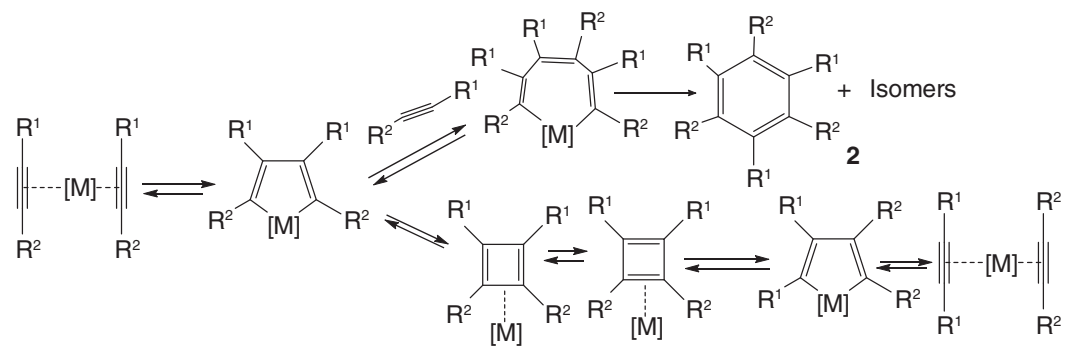

Figure 4

Metallacyclopentadiene-type mechanism for alkyne metathesis on $\mathrm{Mo}(\mathrm{CO})_{6} / \mathrm{ArOH}-$ based catalysts [28].

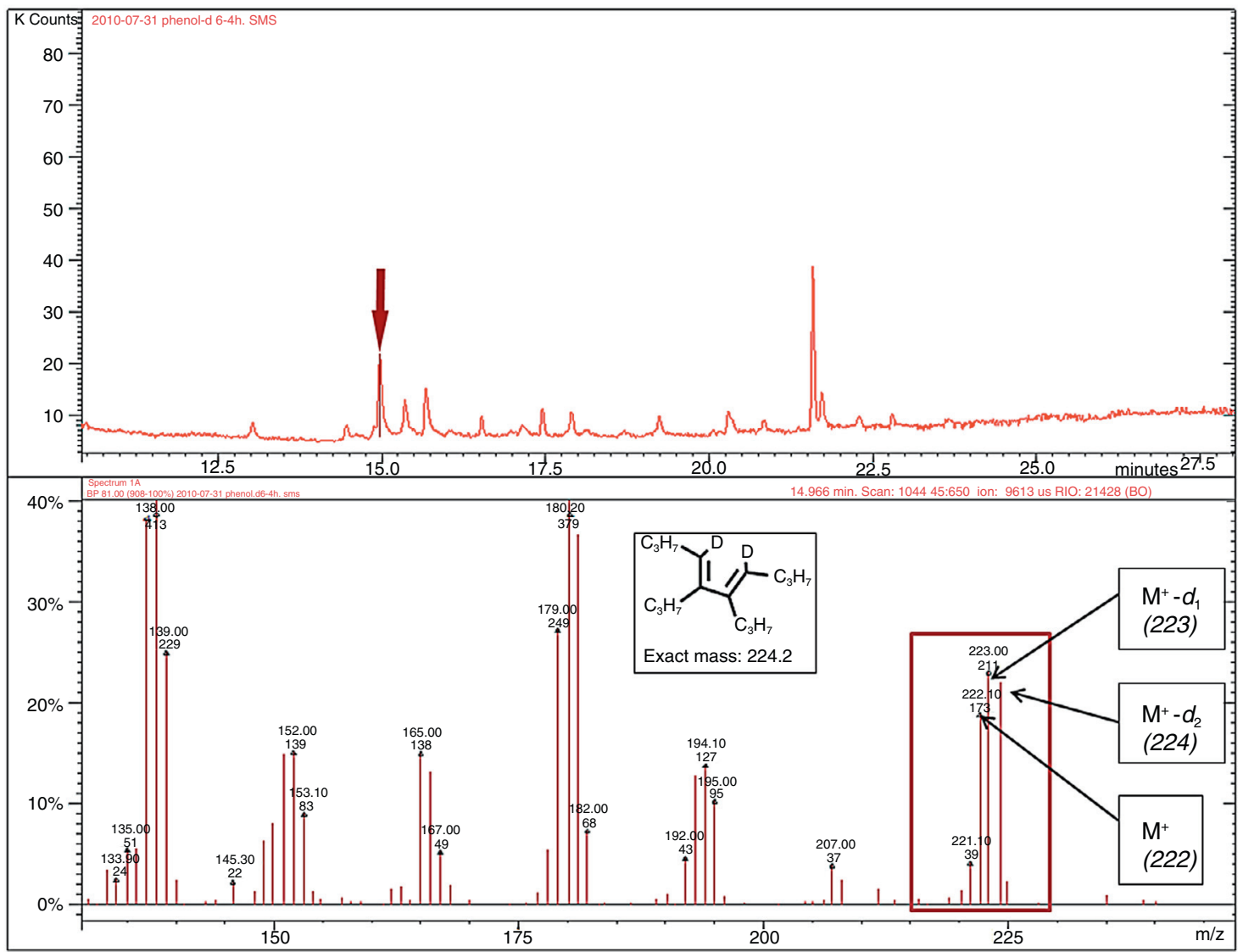

Figure 5

Mass spectrum of 1,2,3,4-tetrapropylbutadiene obtained upon heating $\mathrm{C}_{6} \mathrm{D}_{5} \mathrm{OD}$ and $\mathrm{Mo}(\mathrm{CO})_{6}$ with 4-octyne.

reactivity of the system upon using [alkyne $\left.+\mathrm{Mo}(\mathrm{CO})_{6}\right]$ mixtures previously heated at toluene reflux before phenol addition, which after rapid cooling gave catalytic activity at room temperature, whereas premixing and heating $\mathrm{Mo}(\mathrm{CO})_{6}$ and phenol followed by alkyne addition led to a totally inactive system $[2,3,17]$. The reaction path(s) leading to the aryloxy Mo species described in Figure 6 are in total agreement with these experimental facts.

As for the presence of compound 4 , a mechanistic proposal may be suggested, which would involve an intramolecular insertion reaction of these carbenic moieties into a molybdenacyclopentadiene (Fig. 7). 


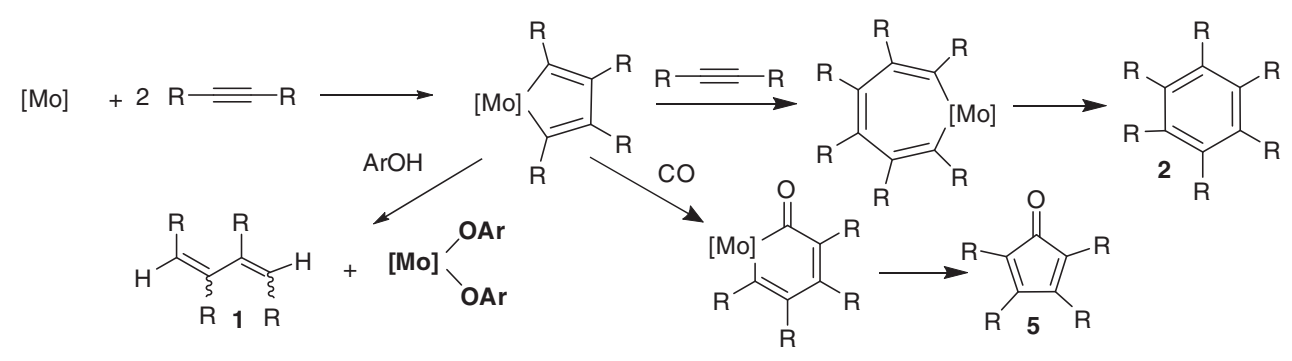

Figure 6

Suggested mechanism for the synthesis of molybdenum aryloxy species from in situ-generated [Mo]/PhOH/alkyne catalytic system.

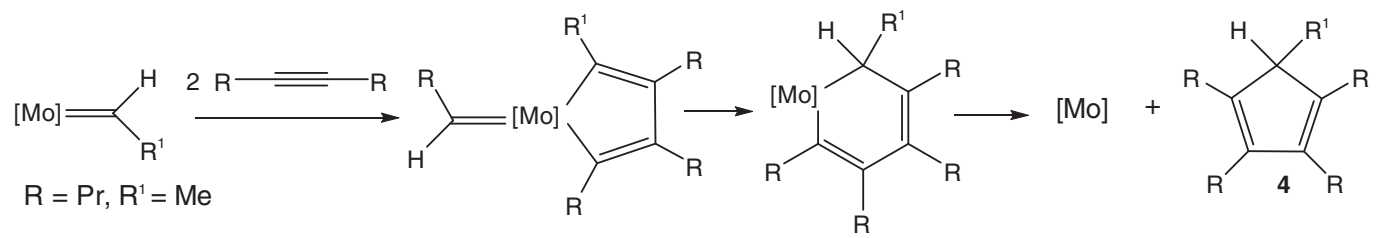

Figure 7

Proposed mechanism of formation of methyl tetrapropyl-cyclopentadiene 4.
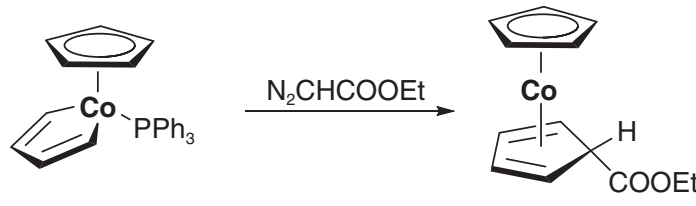

Figure 8

Synthesis of cyclopentadiene compound from the triphenylphosphine (cyclopentadienyl) metallacyclopentadienyl cobalt complex.

The hypothesis of such an intramolecular reaction is supported by earlier work made on a (cyclopentadienyl) metallacylopentadienyl cobalt complex, which upon a diazacarbene addition provides the corresponding cyclopentadiene-substituted compound (Fig. 8) [36].

Compound $\mathbf{6}$ is only present as by product when using $\mathrm{Mo}(\mathrm{CO})_{6}$ as pre-catalyst where due to the presence of carbon monoxide, the cyclopentadienone $\mathbf{5}$ is produced. In Figure 9 is described the way by which this ethylidene compound may be formed, via a Wittig-like reaction with a molybdenacarbene species.

If one assumes that metallacarbyne species are present in the reaction medium, this would indeed explain the presence of metallacarbenes arising from an addition reaction of phenol used in large excess, a process recognized earlier as an entry to metallacarbene species [37]. Note that this reaction path also produces an oxidized $\mathrm{Mo}=\mathrm{O}$

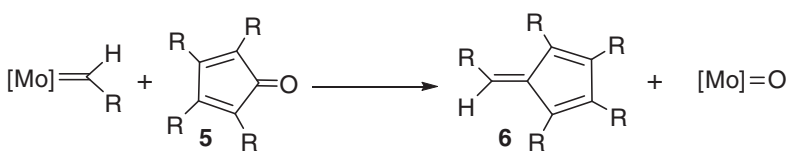

Figure 9

Plausible pathway for the formation of compound $\mathbf{6}$ as by-product.

species, which may be a termination process for metathesis.

The question then would arise to know how metallacarbynes can be involved as active species and how they are formed. As far as all attempts to detect or isolate such intermediates have failed in our hands, probably due to the extreme reactivity of these intermediates, what is following will only aim at suggesting some hypotheses on the formation of metallacarbyne species. One possibility would be to consider a further oxidative addition of phenol on the highly reactive aryloxy $(\mathrm{PhO})_{2} \mathrm{Mo}$ to produce the unstable $\mathrm{Mo}(\mathrm{IV})(\mathrm{PhO})_{3} \mathrm{MoH}$ intermediate or $\mathrm{Mo}(\mathrm{OPh})_{4}$. Both would dimerize and produce the $(\mathrm{PhO})_{3} \mathrm{Mo} \equiv \mathrm{Mo}(\mathrm{OPh})_{3}$ dimer, with concomitant release of dihydrogen or reduction, respectively. A metathesis reaction with the alkyne would give rise to the $(\mathrm{PhO})_{3} \mathrm{Mo} \equiv \mathrm{C}-\mathrm{R}$ initiator of the metathesis process. In support of this assumption, such a metathesis reaction between $\mathrm{Mo} \equiv$ Mo dimers and disubstituted alkynes has indeed been reported (Fig. 10) [38], and already 


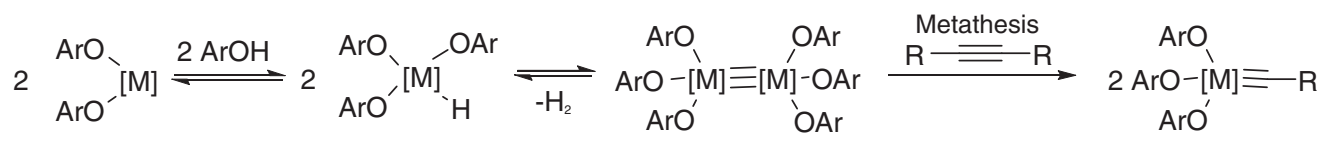

Figure 10

Putative pathway to the in situ production of carbyne initiators.

suggested earlier as a key reaction leading to the active species on $\mathrm{Mo}(\mathrm{CO})_{6} / \mathrm{ArOH}$ systems [29].

On the other hand, if the activities obtained on molybdenum carbonyl-based catalysts are of the same order of those observed on tris(aryloxy)molybdenum carbynes generated in situ from tris amido precursors, the activities obtained on the catalytic systems based on the higher oxidation state dioxo and dinitrosyl $\mathrm{MoO}_{2}(\mathrm{acac})_{2}$ and $\mathrm{MoCl}_{2}(\mathrm{NO})_{2} \mathrm{~L}_{2}-/$ $\mathrm{AlR}_{3} / \mathrm{ArOH}$ combinations are almost two orders of magnitude higher, so that the question would be to know whether the active molybdenum species are the same in both systems and/or if the initiation process generates a similar quantity of active species. Another point worth to be considered is the fact that the alkylation procedure could give rise to another route for the metallacarbyne(s) generation.

As the role of phenol is now assigned differently from the one we proposed earlier, it seems necessary to us to revisit the experimental data that we published more than two decades ago, where a thorough GC analysis of the byproducts in the alkenes and alkyne range was performed on the $\mathrm{MoO}_{2}(\mathrm{acac})_{2} / \mathrm{AlEt}_{3} / \mathrm{PhOH}$ combination [10]. Starting from 4-nonyne as the substrate and conducting the catalytic reaction between 0 and $20^{\circ} \mathrm{C}$ allowed detection of 2-hexenes, 3-heptenes and concomitantly 2-heptyne and 2-hexyne as primary products before the appearance of the expected metathesis products 4-octyne and 5-decyne. That means that the initiation process is different from the one using the $\mathrm{Mo}(\mathrm{CO})_{6} / \mathrm{PhOH}$ catalysts: the presence of these by products is consistent with the formation of not only ethylidene $\mathrm{Mo}=\mathrm{CHMe}$ species via $\mathrm{H}$ abstraction on the $[\mathrm{Mo}] \mathrm{CH}_{2} \mathrm{CH}_{3}$ moiety formed by transalkylation, but also ethylidyne $[\mathrm{Mo} \equiv] \mathrm{C}-\mathrm{Me}$, responsible for the initial production of 2-hexyne and 2-heptyne via reaction with 4-nonyne. As a matter of facts, a fine tuning of the experimental conditions was necessary to achieve good results, i.e. the rigorous respect of the protocol related to the order of addition of the catalyst components, substrate and phenol, otherwise the reaction course deviates. These conditions are as follows:

- premixing of the molybdenum salt and triethylaluminum ( $1 / 6$ ratio) at $0^{\circ} \mathrm{C}$ for $30 \mathrm{~min}$;

- premixing of the alkyne and phenol at room temperature for $10 \mathrm{~min}$;
- injection of the alkylated solution in the alkyne-phenol solution at the desired reaction temperature.

Any other protocol would give either no reaction, or polymerization if phenol is added before the introduction of alkyne.

Considering the literature devoted to the synthesis of alkylidyne molybdenum complexes, it appears that this system is closely related to the synthesis of trisalkoxymolybdenum (VI) alkylidyne complexes [39], where in a first step, using a Grignard reagent, molybdenum salts are alkylated and give stable trisalkylmolybdenum carbynes, via two successive $\alpha-\mathrm{H}$ abstraction reactions. Although the alkylating reagent is here different, a possible way to phenoxymolydenum carbyne active species may therefore come from a first alkylation/alkynylation followed by protonolysis of at least one molybdenum alkyl bonds by phenol in large excess, leading to an alkyl phenoxy metallacarbyne moiety. It appears therefore that most probably, our protocol is a one pot way by which the expected carbyne species are formed. Introducing phenol before the alkyne would rather produce metallacarbenes via reaction with the phenolic reagent with the carbyne moiety. Metallacarbenes are indeed well-known to straightforwardly polymerize alkynes (Fig. 11). Worth to be mentioned here is the fact that tungsten alkylidene have been shown to rapidly interconvert with alkylidyne complexes in the presence of acids, a reaction which may also be here catalyzed by the presence of phenol [37].

Beyond these considerations which show how the alkylation process on high oxidation Mo salts results in the production of carbyne species differently from those arising from $\mathrm{Mo}(\mathrm{CO})_{6}$ alone, another plausible and interesting alternative could be however envisaged considering data already published in the literature on such molybdenum salts/ alkylaluminum devoted to their use as alkene metathesis catalysts, both on dioxo and dinitrosyl complexes. The reaction of dinitrosylmolybdenum complexes with chloroaluminum alkyls has been indeed the subject of several reports, as these were active catalysts in alkene metathesis, as already mentioned $[14,15]$. Of interest is the fact that the dinitrosyl ligands were found to be still present in these reactions, in particular when using alcohols as modifiers [40, 41]. This means that in our system, the ancillary ligands could also be a combination of a dinitrosyl and aryloxy moieties, giving 


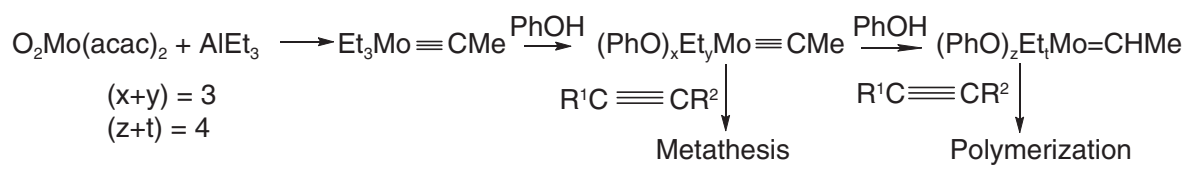

Figure 11

Mechanism proposal for the formation of metallacarbynes and metallacarbenes using the $\mathrm{MoO}_{2}(\mathrm{acac})_{2} / \mathrm{AlEt}_{3} / \mathrm{PhOH}$ catalysts.

rise to much more reactive catalysts than their trisphenoxy congener. Although less documented, the same may apply when using the dioxomolybdenum precatalyst, where one may suggest that an oxo species would also be present together with one aryloxyligand, giving rise to even higher reactivities than the dinitrosyl complex. Some examples in this field have indeed shown that alike imidomolybdenum catalysts, oxo molybdenum complexes in the presence of alkylating agents give rise to efficient olefin metathesis catalysts. One early example is the use of $\mathrm{MoOClR}_{3}$ arising from $\mathrm{MoOCl}_{4}$ as well as mixed tungsten alkoxyalkyl oxo pre-catalysts in the presence of Lewis acids for alkene metathesis [42], and more recently that of $\mathrm{MoOCl}_{4}$ in the presence of alkylating reagents such as $\mathrm{SnBu}_{4}, n$-(BuLi) or $\mathrm{AlEt}_{3}$ and $\mathrm{EtOH}$, providing a nice entry for living alkyne polymerization [43].

\section{CONCLUSION}

Through this paper, one may see that the role of the phenolic and/or siloxy co-catalysts in the in situ synthesis of active species for alkyne metathesis is still not definitively assessed, due to the lack of spectroscopic evidence of the presence of well-defined metallacarbyne or metallacyclobutadiene complexes. However, in contrast with our former assumptions related to the role of the co-catalyst in this reaction, thanks to the analysis of by-products formed during the process, we are now proposing reaction pathways by which ancillary aryloxy or siloxy should be present in the coordination sphere of the metal. The suggested routes by which the metallacarbyne species are formed in these two systems are different, but both are using a process by which phenoxy molybdenum species are formed via protonolysis of a Mo-C bond by the phenolic co-catalyst. The fact that the high oxidation state alkylated systems are much more reactive than the molybdenum carbonyl one certainly comes from the alkylation process, which not only provides the required metal-carbon bond to be protonated, but also from its propensity to readily produce the metallacarbyne. In these in situ systems, we cannot know how much active species are formed from the metal precursor, neither establish a rationalized correlation between the effect of the co-catalyst structure on the activity of a given system, since these cocatalysts intervene in at least two steps in the process: the generation of the active species (thus related to pKa considerations) and afterwards as phenoxy ligands on the metallacarbynes involved in the catalytic cycle (where steric and electronic properties are key parameters). We do hope that this paper dedicated to the memory of Yves Chauvin will open the way to the discovery of more reactive catalysts, together with a further opening towards the pathways related to the formation of the active species, which has been recently considered as something relevant to mystery [44]. The present paper may have unraveled some part of this mystery, about which further studies are underway, still needed to confirm the above-described hypothesis. Indeed, although no definitive proof of the mechanistic proposal described in Figure 4 can be found in the literature, the phenoxy ligand environment may well be a key feature allowing transient and unstable cyclobutadienic complexes to be formed and responsible for the metathesis reaction to occur in these in situ catalytic systems.

\section{ACKNOWLEDGMENTS}

The authors thank the CNRS, the French Ministry of Higher Education and the Institut Universitaire de France for their financial support.

\section{REFERENCES}

1 Chauvin Y., Commereuc D. (1976) Tungsten carbonyl complexes activated by titanium tetrahalides as catalysts for ring-opening polymerization of cyclopentene, Book of abstracts of the $1^{\text {st }}$ Metathesis Symposium, 116-125, Mainz, Germany.

2 Mortreux A., Blanchard M. (1976) Role of phenol in the metathesis reaction of alkynes with catalysts based on Mo $(\mathrm{CO})_{6}$, Book of abstracts of the $1^{\text {st }}$ Metathesis Symposium, 106-116, Mainz, Germany.

3 Mortreux A., Blanchard M. (1974) Metathesis of alkynes on a molybdenum hexacarbonyl-resorcinol catalyst, J. Chem. Soc. Chem. Comm., 786. 
4 Fürstner A. (2013) Alkyne Metathesis on the Rise, Angew. Chem. Int. Ed. 52, 10, 2794-2819.

5 Persich P., Llaveria J., Lhermet R., de Haro T., Stade R., Kondoh A., Fürstner A. (2013) Increasing the stuctural span of alkyne metathesis, Chem. Eur. J., 19, 39, 13047-13058.

6 Lhermet R., Fürstner A. (2014) Cross-metathesis of terminal alkynes, Chem. Eur. J. 20, 41, 13188-13193.

7 Haberlag B., Freytag M., Jones P.J.,Tamm M. (2014) Tungsten and molybdenum 2,4,6-trimethylbenzylidyne complexes as robust pre-catalysts for alkyne metathesis, Adv. Synt. Cat. 356, 6, 1255-1265.

8 Bencheick A., Petit M., Mortreux A., Petit F. (1982) New active and selective catalysts for homogeneous metathesis of disubstituted alkynes, J. Mol. Catal. 15, 93-101.

9 Petit M., Mortreux A., Petit F. (1982) Homogeneous metathesis of functionalized alkynes, J. Chem. Soc., Chem. Comm., 1385-1386.

10 Bages S., Petit M., Mortreux A., Petit F. (1990) Étude de la métathèse des hydrocarbures acétyléniques catalysée par le système $\mathrm{O}_{2} \mathrm{Mo}(\mathrm{acac})_{2}-\mathrm{AlEt}_{3}-\mathrm{PhOH}, J$. Mol Catal. 59, L25-L29.

11 Part of this work has been presented in the XVIII ${ }^{\text {th }}$ International Symposium on Metathesis (ISOM XVIII), Leipzig, 2009.

12 Part of this work has been presented in the XIX $X^{\text {th }}$ International Symposium on Homogeneous Catalysis (ISHC XIX), Ottawa, 2014.

13 Cotton F.A., Johnson B.G.F. (1964) Dichlorodinitrosylmolybdenum, dichlorodinitrosyltungsten, and some of their derivatives, Inorg. Chem. 3, 1609-1612.

14 Zuech E.A. (1968) Homogeneous catalysts for olefin disproportionation, Chem. Commun., 1182.

15 Zuech E.A., Hughes W.B., Kubicek D.H., Kittleman E.T. (1968) Homogeneous catalysts for olefin disproportionation from nitrosyl molybdenum and tungsten compounds, J. Am. Chem. Soc. 92, 528-531.

16 Britovsek G., Gibson V.C., Wass D.F. (1999) The search for new-generation olefin polymerization catalysts: life beyond metallocenes, Angew. Chem. Int. Ed. 38, 428-447.

17 Mortreux A., Delgrange J.C., Blanchard M., Lubochinsky B. (1977) Rôle du phénol dans la réaction de métathèse des hydrocarbures acétyléniques sur les catalyseurs à base de $\mathrm{Mo}(\mathrm{CO})_{6}$, J. Mol. Catal. 2, 73-82.

18 Sashuc V., Ignatowska J., Grela K. (2004) A fine-tuned molybdenum hexacarbonyl/phenol initiator for alkyne metathesis, J. Org. Chem. 69, 7748-7751.

19 Bly R.K., Dyke K.M., Bunz U.H.F (2005) A study of molybdenum catalysts in the polymerization of 2,5 didodecyl-1,4-dipropynylbenzene, J. Organomet. Chem. 690, 825-829.

20 Fisher F.R., Nuckolls C. (2010) Design of living ring-opening living alkyne metathesis, Angew. Chem. Int. Ed. 49, 7257-7260.

21 Coutelier O., Mortreux A. (2006) Alkyne metathesis catalysts: scope and future, J. Mol. Catal. A: Chemical 254, 96-104.

22 Van Huong P. (1963) Influence des solvants sur le spectre infrarouge des carbures acétyléniques. Propriétés acides et basiques de ces carbures, Revue de l'IFP XVIII, 9, 37-51.

23 Yoshida Z., Ishibe N., Ozoe H. (1972) Hydrogen bonding of phenol with acetylenes and allenes, J. Am. Chem. Soc. 94, $14,4948-4952$.

24 Katz T.J., McGinnis J. (1975) The mechanism of the olefin metathesis reaction, J. Am. Chem. Soc. 97, 1592.
25 McCullough L.G., Schrock R.R. (1984) Metathesis of acetylenes by molybdenum (VI) alkylidyne complexes, J. Am. Chem. Soc. 106, 4067-4068.

26 Goodyear J.W., Hemingway C.W., Harrington R.W., Wiseman M.R., Brisdon B.J. (2002) The crystal structure of $\left[\mathrm{Mo}(\mathrm{NCS})(\mathrm{CO})_{2}\left(\eta^{3}-\mathrm{C}_{3} \mathrm{H}_{5}\right)(\mathrm{NCMe})_{2}\right] \cdot \mathrm{MeCN}$ and the reactions of $\left\{\mathrm{Mo}(\mathrm{CO})_{2}\left(\eta^{3}-\mathrm{C}_{3} \mathrm{H}_{5}\right)+\right\}$ containing species with symmetric alkynes, J. Organomet. Chem. 664, 1-2, 176-181.

27 Nishida M., Shiga H., Mori M. (1998) [2+2+2] cocyclisation using $\mathrm{Mo}(\mathrm{CO})_{6}-p-\mathrm{ClPhOH}, J$. Org. Chem. 63, 8606-8608.

28 Kaneta N., Hirai T., Mori M. (1995) Reaction of alkyne having hydroxyphenyl group with $\mathrm{Mo}(\mathrm{CO})_{6}$, Chem. Lett., 627-628.

29 Huc V., Veihofen R., Martin-Jimenez I., Oulié P., Lepetit C., Lavigne G., Chauvin R. (2003) Ether-induced rate enhancement of Mo-catalyzed metathesis under mild conditions, New J. Chem. 27, 10, 1412-1414.

30 Kloppenburg L., Song D., Bunz U.W.F. (1998) Alkyne metathesis with simple catalyst systems: Poly( $p$-phenyleethylenylene)s, J. Am. Chem. Soc. 120, 7973-7974.

31 Ibragimov A.G., Khafizova L.O., Gilfanova G.N., Yakupova L.R., Borisova A.L., Dzhemilev U.M. (2003) Synthesis and transformation of metallacycles -31- Catalysts based on cobalt complexes in reactions of trialkyl-and alkylhaloalanes with olefins, allenes and acetylenes, Russ. Chem. Bull., Int. Ed. 52, 2434-2439.

32 Heppekausen J., Stade R., Kondoh A., Seidel G., Goddard R., Fürstner A. (2012) Optimized synthesis, structural investigations, ligand tuning and synthetic evaluation of silyloxy-based alkyne metathesis catalysts, Chem. Eur. J. 18, 10981-10299.

33 Zhu J., Jia G., Lin Z. (2006) Theoretical investigation of alkyne metathesis catalyzed by W/Mo alkylidyne complexes, Organometallics 25, 7, 1812-1819.

34 Hübel W., Merenyi R.J. (1964) Über Organometall-Komplexe, XIV, Organomolybdän-Verbindungen, J. Organomet. Chem. 2, 213-221.

35 Potenza J.A., Johnson R.J., Chirico R., Efraty A. (1977) Molecular structure of a complex with a $\mathrm{Mo}=\mathrm{Mo}$ bond and a bridging cyclopentadienone group, Inorg. Chem. 16, 9 2354-2359.

36 O'Connor J.M., Pu L., Uhrhammer R., Johnson J.A. (1989) A new mode of carbene reactivity: coupling with two alkynes to generate highly substituted cyclopentadiene products, J. Am. Chem. Soc. 111, 1889-1991.

37 Freudenberger J.H., Schrock R.R. (1985) Preparation of di-tert-butoxytungsten (VI) alkylidene complexes by protonation of tri-tert-butoxytungsten (VI) alkylidyne complexes, Organometallics 4, 1937-1944.

38 Strutz H., Schrock R.R. (1984) Metathesis of molybdenummolybdenum triple bond with acetylenes to give alkylidyne complexes, Organometallics 3, 1600-1601.

39 Mc Cullough L.G., Schrock R.R., Dewan J.C., Murdzek J.C. (1985) Preparation of trialkoxymolybdenum(VI) alkylidyne complexes, their reactions with acetylenes, and the X-Ray structure of $\left.\mathrm{Mo}\left[\mathrm{C}_{3} \mathrm{CMe}_{3}\right)_{2}\right]\left[\mathrm{OCH}\left(\mathrm{CF}_{3}\right)_{2}\right]_{2}\left(\mathrm{C}_{5} \mathrm{H}_{5} \mathrm{~N}\right)_{2}, J$. Am. Chem. Soc. 107, 5987-5998.

40 Keller A., Szterenberg L. (1989) Dialkoxydinitrosylmolybdenum compounds as olefin metathesis precatalysts: catalyst formation and electronic structure, J. Mol. Catal. 57, 207-220

41 Keller A. (1991) Dinitrosylalkylidene complexes containing $\eta$-alkylalkoxy ligand: synthesis, spectroscopic characterization and metathesis activity, J. Organomet. Chem. 407, 237-246. 
42 Kress J., Wesolek M., Le Ny J.P., Osborn J.A. (1981) Molecular Complexes for Efficient Metathesis of Olefins. The Oxo-ligand as a Catalyst-Cocatalyst Bridge and the Nature of the Active Species, J. Chem. Soc., Chem. Comm. 1039-1040.

43 Hayano S., Masuda T., Ji H., Advincula R.C. (2000) On the role of the catalysts components in the living metathesis polymerization of substituted acetylenes by $\mathrm{MoOCl}_{4}$-based systems, Polymer Bulletin 44, 129-136.
44 Schrock R.R. (2013) Alkyne metathesis by molybdenum and tungsten alkylidyne complexes, Chem. Commun. 49, 5529-5531.

Manuscript submitted in October 2015

Manuscript accepted in November 2015 Published online in March 2016

Cite this article as: J. Geng Lopez, M. Zaranek, P. Pawluc, R.M. Gauvin and A. Mortreux (2016). In Situ Generation of MolybdenumBased Catalyst for Alkyne Metathesis: Further Developments and Mechanistic Insights, Oil Gas Sci. Technol 71, 20. 